\section{Mercury Released From Dental Fillings}

Dear Dr. Whelan:

It was with some surprise and even shock that I read the paper by Hahn et al., Whole body imaging of the distribution of mercury released from dental fillings into monkey tissue (FASEB J. 4, 3256-3260).

The thrust of the paper is that $\mathrm{Hg}$ is released (in dangerous amounts?) from amalgam dental fillings. The work was done on a single monkey! Table 1 of their paper gives those results. Could there have been a Table 2? A long time ago I learned that in doing any statistical analysis one must use the term $\mathrm{N}-1$. In this case $\mathrm{N}-1=0$. I submit that the worth of a paper in which only a single experiment is done and reported approximates the value of that term.

I hope that in the future The FASEB Journal will require the most elementary of scientific requirements before acceptance.

Richard L. Malvin

Professor of Physiology

The University of Michigan School of Medicine Ann Arbor, Michigan 48109, USA

\section{Author's Reply:}

Dear Dr. Whelan:

Our recent study (1) was designed simply as a physics radiographic demonstration of dental amalgam $\mathrm{Hg}$ distribution in a primate body. If this report had been a biological study on the physiological effects of amalgam $\mathrm{Hg}$, then it would have required statistical analysis of data and therefore additional animals. The intact monkey that we used to produce the radiographic images was one of two animals participating in our initial study. These two monkeys were monitored for $\mathrm{Hg}$ exposure by measuring fecal $\mathrm{Hg}$ excretion, which averaged 300 $\mu \mathrm{g} / \mathrm{day}$ for 4 weeks. This was approximately $0.5 \%$ of the total $\mathrm{Hg}$ contained in their amalgam fillings (2). Some organs and tissues were removed from one of these monkeys to determine whether $\mathrm{Hg}$ concentration was sufficient to proceed with the more elaborate expense of recruiting nuclear medicine facilities for imaging.

The purpose of our primate study (1) was to confirm earlier findings that we had first reported in sheep, and we had indicated that sheep may chew more than humans $(3,4)$. Our monkeys had only two daily feeding periods of $25 \mathrm{~min}$ each, which affords considerably less chewing activity than that performed by the average human. If we use the example of kidney concentration of $\mathrm{Hg}$ as an index of amalgam $\mathrm{Hg}$ exposure, then all of the several sheep participating in our pilot studies and the six sheep that we have reported display amalgam $\mathrm{Hg}$ levels of $2000-10,000 \mathrm{ng} / \mathrm{g}$ kidney $(3,4)$. This amount compares favorably to results in five monkeys, which range from 1500-5200 ng amalgam $\mathrm{Hg} / \mathrm{g}$ kidney and that were obtained independently from two different laboratories $(1,5)$. At this juncture we do not believe it is necessary to belabor the point as to the fate of $\mathrm{Hg}$ released in substantial amounts from dental "silver" fillings. Every sheep and monkey demonstrates a consistent $\mathrm{Hg}$ distribution pattern. Dental amalgam is clearly not a stable material, and its $\mathrm{Hg}$ component is readily distributed in a variety of body tissues.

Our focus is now directed at determing whether amalgam $\mathrm{Hg}$ is "bioavailable" to the extent that it could alter normal cell function. One such example in monkeys is the increased $\mathrm{Hg}$ resistance of intestinal bacterial populations we have described in a preliminary report (2). This again is a consistent finding that we have observed in additional monkeys of two primate species, and these repeated observations will be reported in a forthcoming paper. Because amalgam $\mathrm{Hg}$ can cause a marked increase in the intestinal population of $\mathrm{Hg}$ resistant bacteria, which can then transfer such resistance to other bacteria through plasmid exchange, this could be a contributing factor to widespread antibiotic resistance in the human population. Bacteria that are resistant to $\mathrm{Hg}$ can also become resistant to antibiotics.

Perhaps it would be more appropriate for Professor Malvin to convey his "shock" to the American Dental Association, which continues to obfuscate on this issue.

\section{F. L. Lorscheider \\ Professor of Medical Physiology \\ The University of Calgary \\ Calgary, Alberta, Canada T2N 4N1}

\section{REFERENCES:}

1. Hahn, L. J., Kloiber, R., Leininger, R. W., Vimy, M. J., and Lorscheider, F. L. (1990) Whole-body imaging of the distribution of mercury released from dental fillings into monkey tissues. FASEB J. 4, 3256-3260

2. Summers, A. O., Wireman, J., Vimy, M. J., and Lorscheider, F. L. (1990) Increased mercury resistance in monkey gingival and intestinal bacterial flora after placement of dental "silver" fillings. Physiologist 33, A-116 (abstr.)

3. Hahn, L. J., Kloiber, R., Vimy, M. J., Takahashi, Y., and Lorscheider, F. L. (1989) Dental "silver" tooth fillings: a source of mercury exposure revealed by whole-body image scan and tissue analysis. FASEB J. 3, 2641-2646

4. Vimy, M. J., Takahashi, Y., and Lorscheider, F. L. (1990) Maternal-fetal distribution of mercury $(203-\mathrm{Hg})$ released from dental amalgam fillings. Am. J. Physiol. 258, R939-R945

5. Danscher, G., Horsted-Binslev, P., and Rungby, J. (1990) Traces of mercury in organs from primates with amalgam fillings. Exp. Mol. Pathol. 52, 291-299 